\title{
Role of insulin-like growth factor (IGF)-1 in the modulation of renal haemodynamics in Type I diabetic patients
}

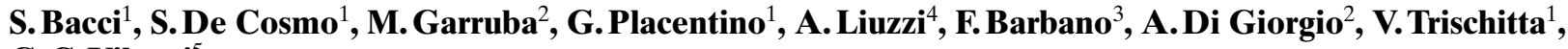 \\ G. C. Viberti ${ }^{5}$ \\ ${ }^{1}$ Division and Research Unit of Endocrinology, Scientific Institute "Casa Sollievo della Sofferenza", San Giovanni Rotondo, Italy \\ ${ }^{2}$ Division and Research Unit of Clinical Chemistry Scientific Institute "Casa Sollievo della Sofferenza", San Giovanni Rotondo, \\ Italy \\ ${ }^{3}$ Department of Nuclear Medicine, Scientific Institute "Casa Sollievo della Sofferenza”, San Giovanni Rotondo, Italy \\ ${ }^{4}$ Division of Endocrinology, Italian Institute of Growth, Scientific Institute "San Giuseppe", Piancavallo, Italy \\ ${ }^{5}$ Unit for Metabolic Medicine, Department of Endocrinology, Diabetes and Internal Medicine, GKT School of Medicine, \\ Guy's Hospital, King's College London, London, UK
}

\section{Abstract}

Aims/hypothesis. We investigated in normotensive Type I (insulin-dependent) diabetic patients with normoalbuminuria the role of growth hormone-induced IGF-1 in the modulation of renal haemodynamics. Methods. We measured glomerular filtration (GFR) and renal plasma flow (RPF) at baseline and at $24 \mathrm{~h}$ after injection of different doses of growth hormone $\left(0.1,0.2,0.4 \mathrm{U} \cdot \mathrm{kg}^{-1} \cdot\right.$ body weight $\left.{ }^{-1}\right)$ in six patients with normal GFR under a euglycaemic clamp. We also examined a 24-h profile of plasma growth hormone and IGF-1 during usual insulin therapy in two other groups each with seven patients with a lower (from 93 to $114 \mathrm{ml} \cdot \mathrm{min}^{-1} \cdot\left(1.73 \mathrm{~m}^{2}\right)^{-1}$ ) and higher (from 121 to $146 \mathrm{ml} \cdot \mathrm{min}^{-1} \cdot\left(1.73 \mathrm{~m}^{2}\right)^{-1}$ ) GFR.

Results. Plasma growth hormone concentrations peaked $2 \mathrm{~h}$ after its injection and plasma concentrations of IGF-1 peaked about $24 \mathrm{~h}$ after the growth hormone injection. There was a significant increase in GFR and RPF $24 \mathrm{~h}$ after the highest dose of the growth hormone injection (corresponding to the highest IGF-1 concentration), from baseline values of $115 \pm 24$ and $536 \pm 141 \mathrm{ml} \cdot \mathrm{min}^{-1} \cdot\left(1.73 \mathrm{~m}^{2}\right)^{-1}$ to $160 \pm 33$ and $657 \pm 137 \mathrm{ml} \cdot \mathrm{min}^{-1} \cdot\left(1.73 \mathrm{~m}^{2}\right)^{-1}$, respectively ( $p<0.01$ for GFR and $p<0.05$ for RPF). No differences were observed in the 24-h profile of growth hormone and IGF-1 plasma concentrations between the two groups; growth hormone and IGF-1 concentrations were lower than those obtained after the injection of $0.4 \mathrm{U} \cdot \mathrm{kg}^{-1} \cdot$ body weight ${ }^{-1}$ of growth hormone.

Conclusion/interpretation. These results show that pharmacological growth hormone-induced IGF-1 concentrations are required to modify renal haemodynamics in Type I diabetic patients and suggest that, under the "physiological" conditions of diabetes, IGF-1 has no role as a mediator of glomerular hyperfiltration. [Diabetologia (2000) 43: 922-926]

Keywords Glomerular filtration rate, renal plasma flow, growth hormone.
Increased glomerular filtration rate (GFR) is an early feature of Type I (insulin-dependent) diabetes mellitus and is believed to play a part in the pathogenesis of diabetic nephropathy [1]. Increased GFR is usually

Received: 3 November 1999 and in revised form: 12 January 2000

Corresponding author: Dr S. Bacci, Division and Research Unit of Endocrinology, Scientific Institute "Casa Sollievo della Sofferenza", Viale Cappuccini 71013 San Giovanni Rotondo, (FG) Italy

Abbreviations: GFR, Glomerular filtration rate; RPF, renal plasma flow; IGF BP-3, insulin-like growth factor-binding protein. associated with increased renal plasma flow (RPF), but the mechanisms responsible for these early renal haemodynamic changes are still only partially understood.

Earlier observations of increased GFR and RPF in acromegaly [2] or after growth hormone injection in normal subjects [3] and reports of increased growth hormone plasma concentrations in diabetic patients $[4,5]$ suggest that growth hormone or IGF-1 may play a part in the glomerular hyperfiltration of diabetes. More recent time-course experiments have shown that IGF-1 is probably the mediator of the renal haemodynamic changes induced by growth hormone and direct IGF-1 infusion induces an increase 
in both GFR and RPF in healthy humans [3, 6-9]. Previous studies in non-diabetic subjects and in diabetic Type I patients have used high doses of either growth hormone or IGF-1, resulting in high plasma concentrations $[3,6-10]$.

Thus, the exact role of physiological or supraphysiological concentrations of growth hormone and IGF1 in the pathogenesis of the renal haemodynamic changes of Type I diabetes is still not clear and needs to be explained. We did a dose response study to evaluate the effect of different growth hormone doses and therefore IGF-1 plasma concentrations on GFR and RPF in Type I diabetic patients with normal GFR. We also examined the 24 -h profile of plasma growth hormone and IGF-1 in two groups of Type I diabetic patients with different rates of glomerular filtration.

\section{Materials and methods}

Subjects. We recruited 20 ( 7 women and 13 men) Type I diabetic patients with normal blood pressure and a normal albumin excretion rate. Of the patients 6 ( 2 women and 4 men) with baseline GFR from 90 to $130 \mathrm{ml} \cdot \mathrm{min}^{-1} \cdot\left(1.73 \mathrm{~m}^{2}\right)^{-1}$ took part in a dose-response study (Table 1$)$ and 14 ( 5 women and 9 men) in a 24-h profile study (Table 2). This latter group was divided into two subgroups with clearly separate GFR values. Type I diabetes was diagnosed by disease onset before the age of 30 years, evidence of ketosis at diagnosis and an absolute need for continuous insulin therapy within 6 months of diagnosis.

All patients gave their informed consent to the study which was approved by the ethics committee of the scientific institute "Casa Sollievo della Sofferenza". None of them were receiving any medication, except insulin.

\section{Experimental procedures}

Dose-response study. Renal haemodynamics were measured under a steady state of water diuresis during a euglycaemic clamp at baseline and $24 \mathrm{~h}$ after injection of growth hormone (Humatrope, Paris, France) at 3 different doses: 0.1, 0.2 and $0.4 \mathrm{U} / \mathrm{kg}$ body weight. Doses were given in random order and at least two weeks elapsed between experiments.

Patients were studied after an overnight fast. On the morning of the test regular insulin (Actrapid HM, Novo, Copenhagen, Denmark) was infused at a mean \pm SD rate of $0.016 \pm$ $0.008 \mathrm{IU} \cdot \mathrm{kg}$ body weight ${ }^{-1} \cdot \mathrm{h}^{-1}$ from 0700 hours to obtain and maintain euglycaemia for the duration of the test. Blood glucose was determined every $5 \mathrm{~min}$ and adjustments were made by the infusion of a $10 \%$ glucose solution whenever needed. The average time for obtaining euglycaemia was $2 \mathrm{~h}$ and this was then maintained for about $1 \mathrm{~h}$ before starting the baseline clearance studies at about 1000 hours. These studies were done under a steady state of water diuresis (urine flow: $7.99 \pm 2.45 \mathrm{ml} / \mathrm{min}$ ), obtained by giving water orally. Glomerular filtration rate and RPF were measured using a primed constant infusion of polyfructosan (Inutest, Boeringer Mannheim, Zurich, Switzerland) and sodium paramminohippurate (PAH, Merck Sharpe and Dohme, Hoddesdon, UK) as described previously $[11,12]$. Briefly, a bolus dose of polyfructosan: $35 \mathrm{mg} / \mathrm{kg}$ and paramminohippurate: $8 \mathrm{mg} / \mathrm{kg}$ was followed by a constant
Table 1. Clinical features of Type I diabetic patients undergoing the dose-response study

\begin{tabular}{lc}
\hline No. (women/men) & $2 / 4$ \\
Age (years) & $29 \pm 5$ \\
Body mass index $\left(\mathrm{kg} / \mathrm{m}^{2}\right)$ & $23 \pm 1$ \\
Duration of diabetes (years) & $7 \pm 3$ \\
$\mathrm{HbA}_{1 \mathrm{c}}(\%)$ & $7.7 \pm 1.6$ \\
$\mathrm{MBP}(\mathrm{mm} \mathrm{Hg})$ & $87 \pm 5$ \\
Albumin excretion rate $(\mu \mathrm{g} / \mathrm{min})$ & $10 \pm 2$ \\
GFR $\left(\mathrm{ml} \cdot \mathrm{min}^{-1} \cdot\left(1.73 \mathrm{~m}^{2}\right)^{-1}\right)($ range $)$ & $90-130$ \\
Insulin dosage $\left(\mathrm{U} \cdot \mathrm{kg}^{-1} \cdot \mathrm{day}^{-1}\right)$ & $0.7 \pm 0.2$ \\
\hline
\end{tabular}

Data are means \pm SD and range for GFR. MBP, mean blood pressure

Table 2. Clinical features of patients recruited in the $24-\mathrm{h}$ profile study

\begin{tabular}{lcc}
\hline & Group 1 & Group 2 \\
\hline No. (women/men) & $3 / 4$ & $2 / 5$ \\
Age (years) & $26 \pm 4$ & $27 \pm 6$ \\
Body mass index $\left(\mathrm{kg} / \mathrm{m}^{2}\right)$ & $23 \pm 2$ & $23 \pm 1$ \\
Duration of diabetes (years) & $7.7 \pm 4$ & $8.4 \pm 2$ \\
$\mathrm{MBP}(\mathrm{mm} \mathrm{Hg})$ & $86 \pm 8$ & $92 \pm 4$ \\
$\mathrm{HbA}_{1 \mathrm{c}}(\%)$ & $7.8 \pm 0.7$ & $7.1 \pm 1.1$ \\
24-h mean blood glucose $(\mathrm{mmol} / \mathrm{l})$ & $8.8 \pm 0.7$ & $9.5 \pm 0.8$ \\
Albumin excretion rate $(\mu \mathrm{g} / \mathrm{min})$ & $10 \pm 3$ & $11 \pm 4$ \\
Insulin dosage $\left(\mathrm{U} \cdot \mathrm{kg}^{-1} \cdot \mathrm{day}^{-1}\right)$ & $0.57 \pm 0.2$ & $0.67 \pm 0.2$ \\
GFR $\left(\mathrm{ml} \cdot \mathrm{min}^{-1} \cdot\left(1.73 \mathrm{~m}^{2}\right)^{-1}\right)($ range) & $93-114$ & $121-146$ \\
\hline
\end{tabular}

Data are means \pm SD and range for GFR. MBP, mean blood pressure

infusion of polyfructosan and sodium paramminohippurate in isotonic saline to maintain a plasma concentration of 350 and $20 \mathrm{mg} / \mathrm{l}$, respectively. After 60 -min equilibration, three 30 -min urine collections were made. At the midpoint of each urine collection period, pulse rate, blood pressure (phase I/V) measured with a standard mercury sphygmomanometer and blood samples were taken for the measurement of sodium paramminohippurate, polyfructosan, glucose and haematocrit. For all variables the mean value of 3 determinations was used for calculations. Samples for growth hormone and IGF-1 were taken at baseline and every $2 \mathrm{~h}$ after the growth hormone injection.

Glomerular filtration rate and RPF were determined at baseline and $24 \mathrm{~h}$ after the growth hormone injection because this injection does not immediately affect GFR and RPF but about $24 \mathrm{~h}$ later, which corresponds to the growth hormoneinduced rise in IGF-1 [3, 9]. During the clearance studies, at baseline and at $24 \mathrm{~h}$ after the injection, patients remained supine standing only to void.

Diurnal profile study. We subdivided 14 patients into two groups with clearly distinct GFR values: 7 patients in group 1 with a lower GFR (range 93-114 $\left.\mathrm{ml} \cdot \mathrm{min}^{-1} \cdot\left(1.73 \mathrm{~m}^{2}\right)^{-1}\right)$ and 7 in group 2 with higher GFR (range $121-146 \mathrm{ml} \cdot \mathrm{min}^{-1}$ $\left.\cdot\left(1.73 \mathrm{~m}^{2}\right)^{-1}\right)$, respectively. These two groups otherwise had similar clinical and metabolic features (Table 2). Plasma samples of growth hormone, IGF-1 and blood glucose were measured every $2 \mathrm{~h}$ during usual insulin therapy for $24 \mathrm{~h}$. Blood pressure (BP) was taken three times during the study.

Measurements and calculations. Patients were screened for GFR by ${ }^{51} \mathrm{Cr}$ EDTA plasma clearance [13].

Plasma and urine polyfructosan were measured after perchloric acid hydrolysis using a centrifugal analyser [11] (Cobas 
Mira Roche Diagnostica, Welwyn Garden City, Herts, UK). Sodium paramminohippurate in plasma and urine was measured using a reported method adapted for use on a Cobas Bio centrifugal analyser (Roche Diagnostica) [12]. Inter-assay and intra-assay coefficients of variation were 3.6 and $3.1 \%$ for polyfructosan and 4.0 and $3.1 \%$ for sodium paramminohippurate. Glomerular filtration rate and RPF were calculated as the clearances using the standard formula $\mathrm{UV} / \mathrm{P}$ and corrected to $1.73 \mathrm{~m}^{2}$ body surface area.

Plasma concentrations of growth hormone were measured by a two-site immunoenzymometric assay (Aia-Pack $\mathrm{HGH}$ Tosoh, Tokyo, Japan), inter-assay and intra-assay coefficents of variation were from 4.2 to $5.4 \%$ and from 2.6 to $3.3 \%$, respectively [14]. Plasma IGF-1 concentrations were measured by extraction radioisotopic assay (Nichols Institute Diagnostics, San Juan Capistrano, Calif., USA). This assay uses a highly specific anti-IGF-1 antibody which does not cross-react with the binding proteins or other peptides; inter-assay and intra-assay coefficients of variation were from 5.2 to $8.4 \%$ and from 2.4 to $3.0 \%$, respectively [15]. Insulin-like growth factor binding protein 3 (IGFBP-3) was measured by competitive protein-binding radioimmunoassay (Nichols institute Diagnostics); inter-assay and intra-assay variation ranges were 3.8$7.3 \%$ and $5.3-6.3 \%$, respectively. Blood pressure (phase I/V) was measured with a standard mercury sphygmomanometer and mean blood pressure was the diastolic blood pressure plus one-third of the pulse pressure difference. Glycated haemoglobin $\left(\mathrm{HbA}_{1 \mathrm{c}}\right)$ was determined by high-pressure liquid chromatography after removal of the labile fraction (HPLC Diamat Analyzer, Bio-Rad, Richmond, Calif., USA). Urinary albumin concentration was determined by the nephelometric method (Behring Nephelometer Analyzer, Behring, Marburg, Germany). Serum creatinine was measured with the Jaffe reaction-rate method (Hitachi 737 Autoanalizer, Tokyo, Japan).

Statistical analysis. Data are presented as means \pm SD or range as reported.

Two-way ANOVA was used to evaluate the response of GFR and RPF and the growth hormone, IGF-1 plasma concentrations after the injection of growth hormone at different doses and to test the differences between the data of the two groups in the 24 -h profile study. Statistical significance was defined as $p$ less than 0.05 .

\section{Results}

Dose response study. Baseline plasma growth hormone concentration rose from $1.5 \pm 1.6$ to a peak of $13.3 \pm 2.5,29.3 \pm 15$ and $149 \pm 31.6 \mathrm{ng} / \mathrm{ml} 2 \mathrm{~h}$ after $0.1,0.2$ and $0.4 \mathrm{U} / \mathrm{kg}$ body weight of injection of growth hormone, respectively and returned to baseline after $16 \mathrm{~h}$ (Fig. 1). Baseline IGF-1 concentrations $(227 \pm 58 \mathrm{ng} / \mathrm{ml})$ increased $8 \mathrm{~h}$ after injection, peaked at $24 \mathrm{~h}$ and were sustained for up to $32 \mathrm{~h}$ (Fig. 1). The plasma concentration of IGF-1 at $24 \mathrm{~h}$ was higher after $0.4 \mathrm{U} / \mathrm{kg}$ body weight injection of growth hormone than the other two growth hormone doses $(248 \pm 19$ vs $282 \pm 93$ vs $355 \pm 104$ after $0.1,0.2$ and $0.4 \mathrm{U} / \mathrm{kg}$ body weight, respectively, $p<0.05$ ).

Baseline values of GFR and RPF were $115 \pm 24$ and $536 \pm 141 \mathrm{ml} \cdot \mathrm{min}^{-1} \cdot\left(1.73 \mathrm{~m}^{2}\right)^{-1}$, respectively and they remained unchanged at $24 \mathrm{~h}$ in response to

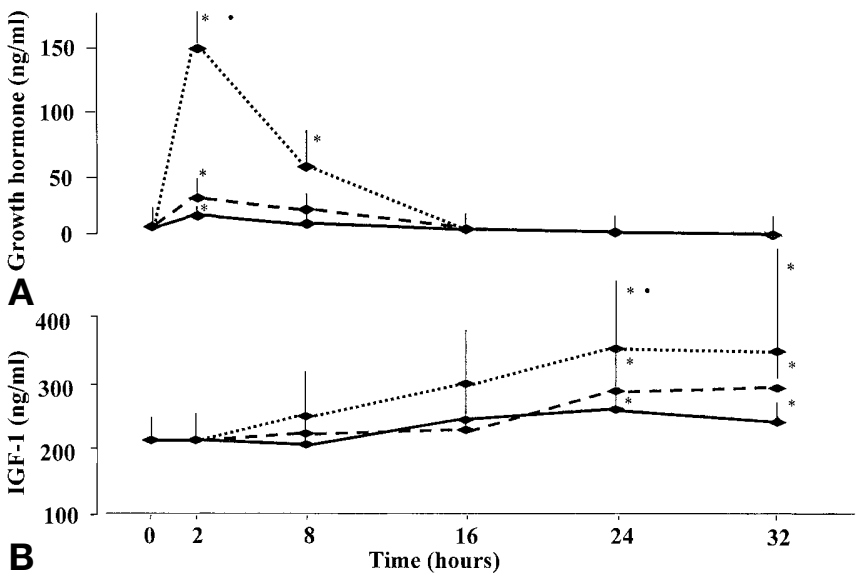

Fig. 1A, B. Serum growth hormone (A) and insulin-like growth factor-1 (IGF-1) (B) concentrations in six Type I diabetic patients before $(O)$ and after growth hormone injection at three different doses: $0.1 \mathrm{U} / \mathrm{kg}(-), 0.2 \mathrm{U} / \mathrm{kg}(---)$, $0.4 \mathrm{U} / \mathrm{kg}$ body weight $(\boldsymbol{\omega})$. Values are means \pm SD. A: ${ }^{*} p<0.01$ vs time $0 ;{ }^{*} p<0.01$ between doses. B: $* p<0.05$ vs time 0 and $p<0.05$ between doses

0.1 and $0.2 \mathrm{U} / \mathrm{kg}$ body weight of injection of growth hormone but increased significantly in response to that of $0.4 \mathrm{U} / \mathrm{kg}$ body weight to $160 \pm 33(p<0.01)$ and $657 \pm 13 \mathrm{ml} \cdot \mathrm{min}^{-1} \cdot\left(1.73 \mathrm{~m}^{2}\right)^{-1}$, respectively $(p<0.05)$ (Fig. 2). This increase was concomitant with the highest IGF-1 concentration.

There were no significant differences in haematocrit ( $39 \pm 1 \%$ vs $41 \pm 3$ vs $42 \pm 3$ ), mean blood pressure (91 \pm 7 vs $87 \pm 5$ vs $87 \pm 4 \mathrm{mmHg})$ and in changed blood glucose values ( $6 \pm 1$ vs $6.8 \pm 1$ vs $6.3 \pm$ $0.5 \mathrm{mmol} / \mathrm{l})$ after the three different growth hormone doses, respectively.

Diurnal profile study. No differences were observed in growth hormone, IGF-1 plasma concentrations between the two groups with lower and higher GFR during the 24-h period (Fig. 3). In addition no significant difference was observed between the two groups in plasma IGFBP-3 values $(6.12 \pm 2.6 \mu \mathrm{g} / \mathrm{ml}$ for lower GFR and $5.17 \pm 1.64 \mu \mathrm{g} / \mathrm{ml}$ for the higher GFR group). Of note, the average IGF-1 concentration during the 24-h period in both groups was $235 \pm 87$ $\mathrm{ng} / \mathrm{ml}$, a value which is very similar to the peak $24-\mathrm{h}$ values of IGF-1 of $248 \pm 19 \mathrm{ng} / \mathrm{ml}$, reached after injection of $0.1 \mathrm{U} / \mathrm{kg}$ body weight of growth hormone. There was no correlation between GFR values and either growth hormone or IGF-1 concentrations.

\section{Discussion}

In normal subjects growth hormone treatment affects GFR and RPF through induction of IGF-1 secretion $[3,9]$. The pathogenic relevance of this to the glomerular hyperfiltration in diabetes is, however, uncertain. 


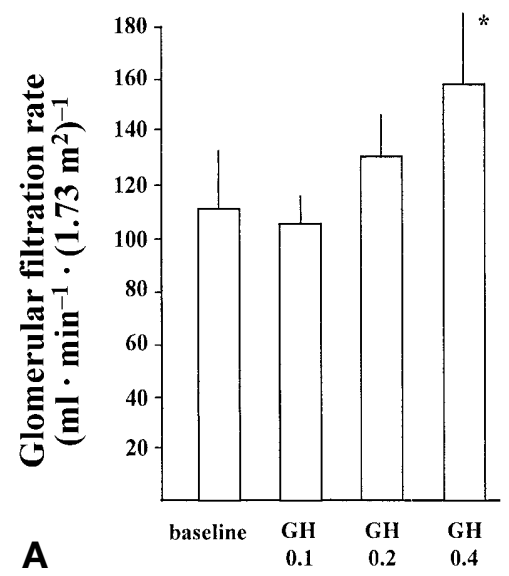

Fig. 2A, B. Glomerular filtration rate $(\mathbf{A})$ and renal plasma flow (B) in six Type I diabetic patients before (baseline) and $24 \mathrm{~h}$ after growth hormone $(\mathrm{GH})$ injection at three different doses given as $\mathrm{U} / \mathrm{kg}$ body weight. Values are means $\pm \mathrm{SD}$. $* p<0.01$ for GFR and $p<0.05$ for RPF vs baseline and other doses

Previous studies in normal subjects and in diabetic patients have used high doses of growth hormone and IGF-1 [3, 6-10]. Our dose-response study in diabetic patients shows that only the highest dose $(0.4$ $\mathrm{U} / \mathrm{kg}$ body weight) of growth hormone injection produces a statistically significant increase in GFR and $\mathrm{RPF}$. This dose resulted in peak growth hormone and IGF-1 concentrations of $149 \mathrm{ng} / \mathrm{ml}$ and $355 \mathrm{ng} /$ $\mathrm{ml}$, respectively which are clearly supraphysiological.

By contrast, no statistically significant effect on GFR and RPF were observed after lower doses of

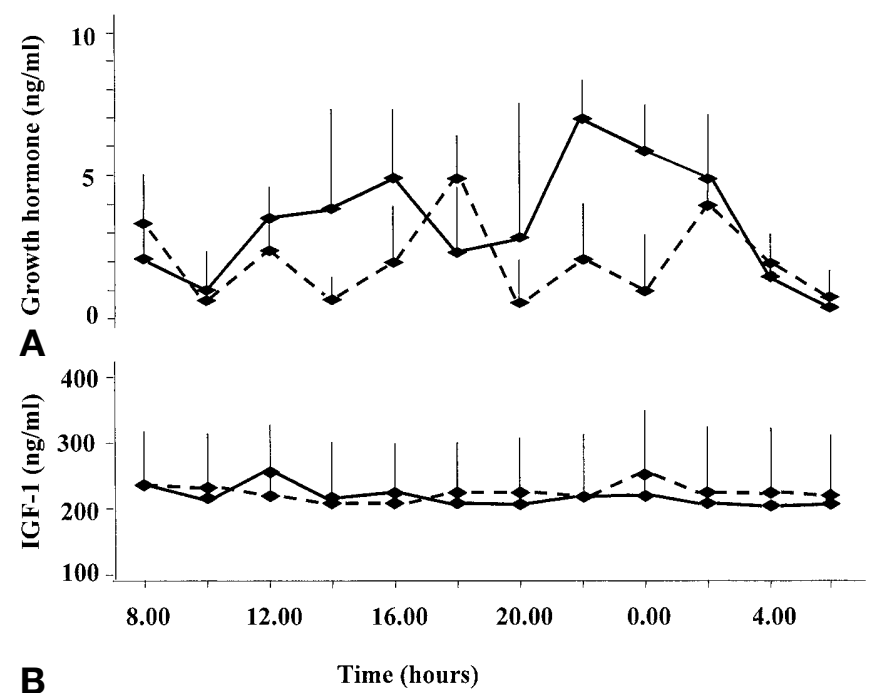

Fig.3 A, B. Serum growth hormone (A) and insulin-like growth factor-1 (IGF-1) (B) concentrations during a 24-h period in seven Type I diabetic patients with lower (-) and seven with higher (-- $)$ glomerular filtration rate

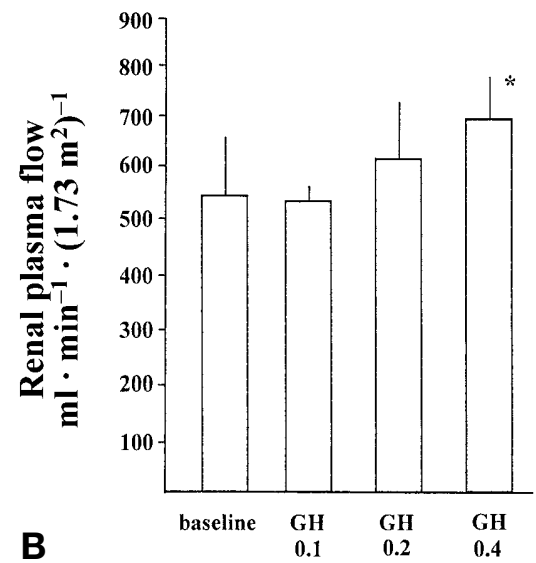

growth hormone injection when more near-physiological concentrations of growth hormone and IGF-1 were obtained. Moreover, time-controlled experiments by other authors [6] showed no change in renal haemodynamics over the time span of our observation. The small numerical increase in GFR and RPF $24 \mathrm{~h}$ after $0.2 \mathrm{U} / \mathrm{kg}$ body weight of growth hormone injection was not significant ( $p>0.2$ for both ) and corresponded to mean IGF-1 concentrations of $282 \pm 92 \mathrm{ng} / \mathrm{ml}$, clearly above those $(237 \pm 103 \mathrm{ng} / \mathrm{ml})$ obtained in the 24-h diurnal profile in the group with the higher GFR.

Other factors that can independently affect renal haemodynamics such as blood glucose concentration, blood pressure and haematocrit (plasma volume) did not differ between the three different doses of growth hormone injection.

The modification patterns of growth hormone and IGF-1 concentrations in our study are similar to that described previously by other authors in normal subjects $[3,9]$. The concomitance of hormonal variations with the changes in renal haemodynamics is also similar to that of previous studies supporting the view that IGF-1 is the mediator of the effects of growth hormone on GFR and RPF [3, 6-9]. Quantitatively, the changes in growth hormone concentration were also similar to those for equivalent injection doses in another [3]. After the $0.4 \mathrm{U} / \mathrm{kg}$ body-weight dose we observed a 96-fold rise from baseline by $6 \mathrm{~h}$ and the investigators in that study found a 95-fold increase above baseline after an injection of $0.15 \mathrm{mg} / \mathrm{kg}$ body weight. The changes in plasma IGF-1 were, however, considerably different. We observed a $54 \%$ peak increase whereas those investigators noted a $159 \%$ rise [3]. This discrepancy between Type I diabetic patients and normal subjects in the IGF-1 rise induced by growth hormone is likely to be due to hepatic growth hormone receptor resistance which is reported in diabetes [16]. This further highlights the diversity of the "physiological" milieu in diabetic patients compared with normal subjects and underscores the importance of establishing the relevance of putative mediators in the specific subject group in which the 
abnormality (in this case glomerular hyperfiltration) occurs. It could be argued that if the IGF1 effects are mediated not only by its circulating concentrations but, to a significant extent, by the renal concentration of IGF-1, by a paracrine mechanism, plasma levels would be an inaccurate measure of local physiological effects $[17,18]$. Both circulating and renal concentrations of IGF-1 are, however, directly dependent on growth hormone plasma concentrations $[19,20]$. The effect on renal haemodynamics observed by us was obtained at growth hormone concentration well into the supraphysiological range for Type I diabetic patients. The diurnal studies confirm previous observations from our group that there is no difference in 24-h growth hormone profiles between Type I diabetic patients with or without hyperfiltration [21] and show that 24-h IGF-1 profiles are equally unrelated to GFR status. The 24-h profiles show that the IGF-1 concentrations in Type I diabetic patients, whatever the GFR, are lower than those required to induce changes in GFR and RPF.

In conclusion, pharmacological concentrations of IGF-1 induced by growth hormone are required to increase the GRF and RPF in diabetic patients. Prevailing concentrations of growth hormone and IGF-1 in Type I diabetes do not seem to contribute to the increased glomerular filtration. This suggests that increases in the glomerular filtration rate of these patients is not mediated by IGF-1.

Acknowledgements. This work was supported by a grant from the Italian Department of Health. Part of this work has been presented in abstract form at the 16th IDF Congress, Helsinki, 1997.

\section{References}

1. Mogensen CE, Christensen CK (1984) Predicting diabetic nephropathy in insulin-dependent patients. N Engl J Med 311: 89-93

2. Ikkos D, Ljunggren H, Luft R (1956) Glomerular filtration rate and renal plasma in acromegaly. Acta Endocrinol 21: 226-236

3. Hirschberg R, Rabb H, Bergamo R, Kopple J (1989) The delayed effect of growth hormone on renal function in humans. Kidney Int 35: 865-870

4. Hayford JT, Danney MM, Hendrix JA, Thompson RG (1980) Integrated concentration of growth hormone in juvenile-onset diabetes. Diabetes 29: 391-398

5. Asplin CM, Faria ACS, Carlsen EC et al. (1989) Alterations in the pulsatile mode of growth hormone release in men and women with insulin-dependent diabetes mellitus. J Clin Endocrinol Metab 69: 239-245
6. Hirschberg R, Brunori G, Kopple J, Guler HP (1993) Effects of insulin-like growth factor I on renal function in normal men. Kidney Int 43: 387-397

7. Guler HP, Zapf J, Froesch ER (1987) Short-term metabolic effects of recombinant human insulin-like growth factor I in healthy adults. N Engl J Med 317: 137-140

8. Giordano M, De Fronzo R (1995) Acute effect of human recombinant insulin-like growth factor I on renal function in humans. Nephron 71: 10-15

9. Hirschberg R, Kopple J (1988) Increase in renal plasma flow and glomerular filtration rate during growth hormone treatment may be mediated by insulin-like growth factor I. Am J Nephrol 8: 249-253

10. Christiansen JS, Gammelgaard J, Frandsen M, Orskov H, Parving HH (1982) Kidney function and size in Type I (insulin-dependent) diabetic patients before and during growth hormone administration for one week. Diabetologia 22: 333-337

11. Dalton RN, Turner C (1987) A sensitive method for the measurement of inulin. Ann Clin Biochem 24[Suppl 1]: 231

12. Bratton AC, Marshall EK (1938) A new coupling component for sulphanilamide determination. J Biol Chem 128: 537-550

13. Brochner-Mortensen J (1972) A simple method for determination of glomerular filtration rate. Scand J Clin Lab Invest 30: $271-274$

14. Raiti S, Tolman RA (1986) Human growth hormone. Plenum Press, New York

15. Underwood LE, Murphy MG (1987) Radioimmunoassay of the Somatomedins/insulin-like growth factors. In: Patrano C, Peskar BA (eds) Radioimmunoassay in Basic and Clinical Pharmacology. Springer, Berlin Heidelberg New York, pp 561-574

16. Haal K, Joansson BL, Povoa G, Thalme B (1989) Serum levels of insulin-like growth factor (IGF) I, II and IGF binding protein in diabetic adolescents treated with continuous subcutaneus insulin infusion. J Intern Med 225: 273-278

17. D'Ercole AJ, Stiles AD, Underwood LE (1984) Tissue concentration of somatomedin C: further evidence for multiple sites of syntesis and paracrine/autocrine mechanism of action. Proc Natl Acad Sci USA 81: 935-939

18. Schimpff RM, Donnadieu M, Duval M (1980) Serum somatomedin $\mathrm{C}$ activity measured as sulphation factor in peripheral, hepatic and renal veins in normal mongrel dogs: early effects of intravenous injection of growth hormone. Acta Endocrinol 93: 155-161

19. Stiles AD, Sosenko IRS, D'Ercole AJ, Smith BT (1985) Relations of kidney tissue somatomedin-C/insulin like growth factor I to postnephrectomy renal growth in the rat. Endocrinology 117: 2397-2401

20. Skottner A, Clark RG, Fryklund L, Robinson ICAF (1989) Growth responses in a mutant dwarf rat to human growth hormone and recombinant human insulin-like growth factor I. Endocrinology 124: 2519-2526

21. Wiseman MJ, Redmond S, House F, Keen H, Viberti GC (1985) The glomerular hyperfiltration of diabetes is not associated with elevated plasma levels of glucagon and growth hormone. Diabetologia 28: 718-721 